\title{
Anti Obesogenic Potential of Caralluma acutangula Bioactive Fractions
}

Dramane Paré ${ }^{1 *}$, Jotham Yhi-Pênê N'do ${ }^{1}$, Adama Hilou ${ }^{1}$, Nogma Ernest Sombie ${ }^{1}$, Mabozou Kpemissi ${ }^{2}$, Sévastre Bogdan $^{3}$

${ }^{1}$ Laboratory of Biochemistry and Applied Chemistry (LABIOCA), UFR/SVT, 09 BP 848, Ouagadougou 09, University of Ouagadougou, Ouagadougou, Burkina Faso

${ }^{2}$ Faculty of Sciences, University of Lome, Togo

${ }^{3}$ Faculté de Médecine vétérinaire, Université de science agronomique et de Médecine vétérinaire Cluj-Napoca, Romanie

\author{
DOI: $10.36348 / \mathrm{sijb} .2020 . \mathrm{v} 03 \mathrm{i} 08.004$ \\ | Received: 04.07.2020 | Accepted: 11.07.2020 | Published: 29.08 .2020
}

*Corresponding author: Dramane Paré

\section{Abstract}

Obesity is a chronic condition characterized by excess body fat which results in an increase in the body weight of patients. $C$ acutangula is a medicinal plant used in traditional medicine in Burkina Faso for the management of weight gain. The objective of this study was to determine the anti obesity potential of the bioactive fractions of $C$. acutangula extract. The ethanolic extract of $C$. acutangula was fractionated to obtain the hexanic, dichloromethane, ethyl acetate, butanol and aqueous fractions. The effect of these fractions on weight gain, food intake and lipid biochemical parameters were determined in vivo. The inhibitory activity of digestive enzymes (pancreatic lipase, trypsin) and the antioxidant potential were evaluated for these fractions. The butanolic fraction showed the best activity with an inhibition of $68.20 \pm$ $3.4 \%$ at $100 \mu \mathrm{g} / \mathrm{ml}$. The ethyl acetate fraction gave the best activity on reducing body weight with $18.11 \%$ reduction to $50 \mathrm{mg} / \mathrm{kg}$ of body weight against the control (hyperlipid diet) which gave increases in weight of $34.83 \%$ respectively. The ethyl acetate fraction at 25 and $75 \mathrm{mg} / \mathrm{kg}$ of body weight and the butanolic fraction at $50 \mathrm{mg} / \mathrm{kg}$ showed the best reductions in the triglyceride level with respectively $111.89 \pm 28.6 ; 108.35 \pm 10.5$ and $108.9 \pm 10.21 \mathrm{mg} / \mathrm{dl}$ against the control which gave a rate of $280 \pm 8.43 \mathrm{mg} / \mathrm{dl}$. Best activities on cholesterol levels, HDLc and LDLc have been observed. For the antioxidant effect, the fractions caused a reduction in the level of MDA and an induction of the production of catalase. These results demonstrate that the ethyl acetate and butanolic fractions contain antiobesity molecules and could therefore be used in the implementation of a phytomedicine.

Keywords: Obesity, medicinal plant, food intake, C. acutangula, antioxidant potential, phytomedicine.

Copyright @ 2020: This is an open-access article distributed under the terms of the Creative Commons Attribution license which permits unrestricted use, distribution, and reproduction in any medium for non-commercial use (NonCommercial, or CC-BY-NC) provided the original author and source are credited.

\section{INTRODUCTION}

Obesity is a chronic disease, which exists in both developed and developing countries and affects both children and adults. Indeed, it is now so widespread that it replaces the traditional public health problems of undernutrition and infectious diseases, and is one of the most important factors of bad health.

Obesity is often defined simply as an abnormal or excessive accumulation of fat in adipose tissue, which can lead to health problems [1]. It is the main risk factor for metabolic diseases such as hyperlipidemia, hypertension, osteoarthritis, dyslipidemia, type 2 diabetes mellitus, arteriosclerosis, nutritional deficiencies, obstructive sleep apnea, musculoskeletal complications and cancers. Orthopedic problems in children are also linked to obesity $[2,3]$.

Obesity / overweight are an emerging problem in Africa. In some cultures, fat or "plump" women are seen as a sign of wealth, fertility and beauty while lean individuals are seen as malnourished or as a sign of ill health. This is a climate conducive to the increase in the rate of the disease.

This pathology generally occurs following excessive consumption of energy (food intake), unlike energy expenditure (loss of energy via metabolic and physical activity), the cause of obesity is very complex and includes genetic factors , physiological, environmental, psychological, social, economic and even political aspects that interact to varying degrees to promote the development of obesity $[4,5]$.

In order to remedy this, several means are used such as physical exercises, dietetics, surgical treatments, pharmaceutical drugs, phytotherapy, etc. On the market, pharmaceutical drugs are most often of synthetic origin, but most of these products have been withdrawn due to multiple harmful side effects [6]. 
Currently, due to potentially dangerous side effects, the need for natural obesity products is being explored, which may be an alternative strategy for developing effective and safe anti-obesity drugs [7]. Plants have always been the main source (up to 90\%) of drugs or care for the treatment of different pathologies of the population in many African countries [8]. Some well-known herbal medicines are already used in the treatment of obesity [9]. The anti-obesity activity of these species of medicinal plants is certainly linked to the presence of metabolites such as polyphenols, glycosiled pregnans, mannans capable of reducing the level of triglycerides, glucose, cholesterol or inhibiting the enzymes involved in lipid metabolism such as pancreatic lipase, lipoprotein lipase and glycerophosphate dehydrogenase or to increase energy expenditure [10].

Caralluma acutangula is a species of plant particularly used in the north of Burkina Faso for the management of weight gain. This species is rich in pregnans glycosides which are molecules which have shown anticancer, anti-obesity, appetite suppressant, antitrypanosomal activities [11]. The objective of this study was therefore to determine the anti-obesity potential in vitro and in vivo of the bioactive fractions of C. acutangula

\section{MATERIAL AND METHODS Biological Material}

The whole plants of $C$. acutangula were harvested at Gorom gorom (a locality located in northern Burkina Faso at $400 \mathrm{Km}$ on the road Ouagadougou $\left(12^{\circ} 29^{\prime} 42.7 \mathrm{~N}, 1^{\circ} 24^{\prime} 1.2 \mathrm{~W}\right)$ during the period of March to April 2017. The specie was authenticated and a herbarium was deposited in the UFR / SVT under identification codes ID 17049.

Male and female mice (NMRI) from the pet shop at the University of Ouagadougou ; Burkina Faso were acclimated for one week $\left(25^{\circ} \mathrm{C}\right.$ with a circadian cycle) for various in vivo tests.

All experimental animal protocols had complied with the instructions of the Institutional Animal Ethics Committee (directive 2010/63/EU on protection of animals used for scientific purposes). Ethical approval code: 2010/63/EU, Date of approval: 20 October 2010. The institutional animal ethical guidelines were strictly observed. All authors hereby declare that "Principles of laboratory animal care were followed, as well as specific national laws where applicable.

\section{Fractionation of Extract (Liquid-Liquid)}

The ethanolic extract is fractionated using a solvents with increasing polarity (hexane, dichloromethane, ethyl acetate and butanol) using a separating funnel. The crude extract is initially dissolved in water and then mixed with hexane (V/V), after decantation the upper organic phase is recovered. This step is redone three times. The hexane is subsequently evaporated under reduced pressure to dryness at $40^{\circ} \mathrm{C}$ by a rotary evaporator, and the resulting extract is considered to be the hexane fraction (FH). The lower aqueous phase is subjected to further fractionation by the dichloromethane, ethyl acetate and butanol to give respectively the dichloromethane (FDCM), ethyl acetate and butanolic fractions following the same steps as the first fractionation with hexane. The resulting raffinate represents the residual aqueous fraction (FAQ). The solvents were removed under reduced pressure and the concentrates were dried.

\section{Activity 1: Inhibition of Digestive Enzymes Pancreatic Lipase Inhibition}

The activity of the pancreatic lipase produced according to the method defined by Changhyun et al., 2012 [12]. The activity is measured using p-nitrophenyl butyrate (p-NPB) as a substrate. Porcine pancreatic lipase solutions $(1 \mathrm{mg} / \mathrm{ml})$ are prepared in $0.1 \mathrm{mM}$ potassium phosphate buffer $(\mathrm{pH} \mathrm{6.0)}$ and the solutions are stored at $-20^{\circ} \mathrm{C}$. To determine the inhibition activity of lipases, extracts (final concentration of 100 $\mu \mathrm{g} / \mathrm{ml}$ ) or Orlistat as a positive control were preincubated with porcine pancreatic lipase for $1 \mathrm{~h}$ in potassium phosphate buffer $(0.1 \mathrm{mM}, \mathrm{pH} 7.2)$ at $30{ }^{\circ} \mathrm{C}$ before assaying the activity of porcine pancreatic lipase. The reaction then began following the addition of $0.1 \mu \mathrm{l}$ pNPB as a substrate, all in a final volume of $100 \mu 1$. After incubation at $30^{\circ} \mathrm{C}$ for $5 \mathrm{~min}$, the amount of $\mathrm{p}$ nitrophenol released in the reaction was measured at $405 \mathrm{~nm}$ using a UV-Visible spectrophotometer. The activity of the negative control was also examined with and without an inhibitor. The inhibitory activity (I) was calculated according to the following formula: Percentage of inhibition $(\mathrm{I} \%)=100-((\mathrm{B}-\mathrm{b}) /(\mathrm{A}-\mathrm{a}) \times$ 100)

Where,

A represents the activity without inhibitor, $\mathrm{a}$ is the negative control without inhibitor, $\mathrm{B}$ is the activity of the inhibitor, $\mathrm{b}$ is the negative control with an inhibitor

\section{Trypsin Inhibition}

The activity was carried out according to the method described by Arefrad et al., in 2013 [13]. To measure the inhibitory activity of the extracts on trypsin, $5 \mu \mathrm{g}$ of trypsin (from bovine pancreas, Sigma) and $5 \mu \mathrm{g}$ of total protein extract were combined in an appropriate volume of $0.2 \mathrm{M}$ Tris- $\mathrm{HCl} \mathrm{pH} \mathrm{7,8}$ to obtain a total volume of $800 \mu \mathrm{l}$ of enzyme solution. The trypsin and the extract were incubated for $5 \mathrm{~min}$ before the addition of $160 \mu \mathrm{g}$ of p-nitroanilide $\mathrm{N}$ - $\alpha$-benzoylDL-arginine in $200 \mu \mathrm{l}$ of substrate buffer (Tris- $\mathrm{HCl}$ $\left.0.05 \mathrm{M} \mathrm{pH} 8.2,0.05 \mathrm{M} \mathrm{CaCl}_{2}\right)$. The released pnitroanilide was monitored for $25 \mathrm{~min}$ at $410 \mathrm{~nm}$ using a spectrometer. The activity is expressed in the form of inhibition percentages. 


\section{Activity 2: Reducing activity of body mass and food} intake.

The effect of the extracts on food intake and weight was evaluated according to the method described by: Mei-Yin et al., 2016 [14]. The study uses mice aged 4 to 5 weeks. The animals were divided into five (5) groups of six (6) mice each. A series of three doses $(25,50,75 \mathrm{mg} / \mathrm{kg}$ of body weight) of a preparation of the extracts or fractions was administered to the different groups of animals, with a negative control group which will receive only the vehicle (water) plus standard food and a positive control who received the vehicle and hyperlipid food. The extracts are administered for a volume not exceeding $200 \mu$. The mice were placed 12 hours in the light, 12 hours in the dark and they had free access to food and water. They are treated for a period of 4 weeks.

Group 1: Standard food + force-feeding (Vehicle)

Group 2: Hyperlipid food + force-feeding (Vehicle)

Group 3: Hyperlipid food + force-feeding (Plant extracts at $25 \mathrm{mg} / \mathrm{kg}$ body weight)

Group 4: Hyperlipid food + force-feeding (Plant extract at $50 \mathrm{mg} / \mathrm{kg}$ body weight)

Group 5: Hyperlipid food + force-feeding (Extract of plant at $75 \mathrm{mg} / \mathrm{kg}$ body weight) Composition of the hyperlipid diet

Anorectic activity of the extract (food intake)

It consisted in determining the effect of the extract on the amount of food taken from animals. This involved measuring the total amount of food remaining by weighing each day for each batch. Food consumption = total amount of food given to the animal - amount of food remaining.

Slimming potential of the extract (weight gain)

Determination of body weight: During the 4 weeks of the study period, the body weight of each animal was measured every three days using a standard weighing device. The net weight gain was calculated as follows: Net weight gain = final weight - initial weight

\section{Activity 3: Effect of fractions on serum biochemical parameters}

After four weeks of treatment, the animals are sacrificed after being anesthetized with ketamine (150 $\mathrm{mg} / \mathrm{kg}$ of weight). The blood of the animals was collected by cardiac puncture in dry tubes, centrifuged at $3000 \mathrm{rpm}$ for 5 minutes and the serum were collected in order to assess the enzymatic parameters and the level of lipid indices such as Aspartate Amino Transferase ( AST), Alanine amino Transferase (ALT), cholesterol level, total triglycerides, LDLc by colorimetry using commercial kits.

\section{Activity 4: Effect of the extracts on the hepatic enzyme parameters \\ Superoxide dismutase (SOD) measurement}

The SOD was tested by the standard methods revealed by Misra et al., 1972 [15]. It is based on the inhibition of the transition of epinephrine adrenochron by the enzyme. $0.5 \mathrm{ml}$ of the homogeneous plasma was taken in a container of reaction then $0.5 \mathrm{ml}$ of distilled water to dilute the sample. $0.25 \mathrm{ml}$ of ice-cold ethanol and 0.15 of chloroform was added to precipitate the reaction mixture. The reaction mixture is stirred well for about 5 minutes at 4 degrees $C$. Then centrifuged. The adrenochrone produced in the reaction mixture contains $0.2 \mathrm{ml}$ of EDTA $(0.6 \mathrm{mM}), 0.4 \mathrm{ml}$ of $\mathrm{Na}_{2} \mathrm{CO}_{3}$ $(0.25 \mathrm{M})$ and $0.2 \mathrm{ml}$ of epinephrine $(3 \mathrm{mM})$, the volume final was adjusted to $2 \mathrm{ml}(0.3 \mathrm{ml}$ distilled water $)$ then the absorbance readings were measured at $420 \mathrm{~nm}$ in a UV-Visible spectrometer. The transition from epinephrine to adrenochrome was determined by adding the required amount of enzyme to assess the enzyme activity expressed in terms of unit / minute / $\mathrm{mg}$ of protein.

\section{Catalase Measurement}

Catalase is tested using the standard method given by Beers and Siezer 1952 [16]. The degradation of $\mathrm{H}_{2} \mathrm{O}_{2}$ by addition of the enzyme is followed by absorption of light. The absorption of the peroxide solution in the UV region is determined. A $3 \mathrm{ml}$ of mixture containing $1.9 \mathrm{ml}$ of phosphate buffer $(0.05 \mathrm{M}$, $\mathrm{PH} 7), 1.0 \mathrm{ml}$ of $\mathrm{H}_{2} \mathrm{O}_{2}$ substrate $(30 \mathrm{mM})$ and $0.1 \mathrm{ml}$ of dilute enzyme was used in these assays. Activity was measured as a change in optical activity at a density of $240 \mathrm{~nm}$ at one minute intervals for approximately 3 minutes. Catalase activity was expressed in terms of $\mu \mathrm{mol}$ of $\mathrm{H}_{2} \mathrm{O}_{2}$ consumed / min / $\mathrm{mg}$ of protein.

\section{The Inhibitory Activity of Lipid Peroxidation}

Lipid peroxidation (LPO) of the extracts was determined by the 2-thiobarbituric acid method [17]. Iron dichloride $\left(\mathrm{FeCl}_{2}\right)$ with hydrogen peroxide $\mathrm{H}_{2} \mathrm{O}_{2}$ has been used to induce peroxidation of rat liver homogenate. In this method $0.2 \mathrm{~mL}$ of the extracts $(1.5$ $\mathrm{mg} / \mathrm{mL}$ ) was mixed with $1.0 \mathrm{~mL}$ liver homogenate in $1 \%$ Tris- $\mathrm{HCl}$ buffer $(50 \mathrm{~mm}, \mathrm{pH} 7.40)$, then $50 \mu \mathrm{L}$ of $\mathrm{FeCl}_{2}(0.5 \mathrm{mM})$ and $50 \mu \mathrm{L}$ of $\mathrm{H}_{2} \mathrm{O}_{2}(0.5 \mathrm{mM})$ were added. The mixture was incubated at $37^{\circ} \mathrm{C}$ for 60 minutes, then $1 \mathrm{ml}$ of trichloroacetic acid (15\%) and 1 $\mathrm{ml}$ of 2-thiobarbituric acid TBA $(0.67 \%)$ were added and the mixture is heated in boiling water for 15 minutes. The absorbances were read at $532 \mathrm{~nm}$ using the spectrophotometer. The percentage inhibition of lipid peroxidation is calculated according to the formula: \% Inhibition $=\boldsymbol{A} 0-\boldsymbol{A} 1 \boldsymbol{A} 0 \times 100$ With A0 the percentage inhibition of the negative control, A1 the absorbance of the sample. Quercetin is used as a positive control. The measurements are carried out in triplicate by extract.

\section{RESULTS \\ Inhibition of Digestive Enzymes}

The inhibitory activities of the ethanolic extract of C. acutangula and its Hex, AE, DCM, BUT, AQ fractions against porcine pancreatic lipase are illustrated in FIG. 1. The butanolic fraction showed the 
best activity with an inhibition of $68,20 \pm 3.4 \%$ at $100 \mu \mathrm{g} / \mathrm{ml}$. The crude ethanolic extract also exhibited good activity. Orlistat, a standard pancreatic lipase inhibitor used as an anti-obesity agent, inhibits enzyme activity by $90.15 \pm 2.2$ at a concentration of $10 \mu \mathrm{g} / \mathrm{ml}$. The aqueous fraction showed the lowest activity.
Figure-2 shows the inhibitory power of $C$. acutangula extract and its fractions on the activity of trypsin, a digestive enzyme. The aqueous and hexane fraction showed the best activities with respectively $50.97 \pm 7.02 \%$ and $47.48 \pm 6.8 \%$ of trypsin inhibition. The dichloromethane fraction showed the lowest activity with $26.05 \pm 0.7 \%$ inhibition.

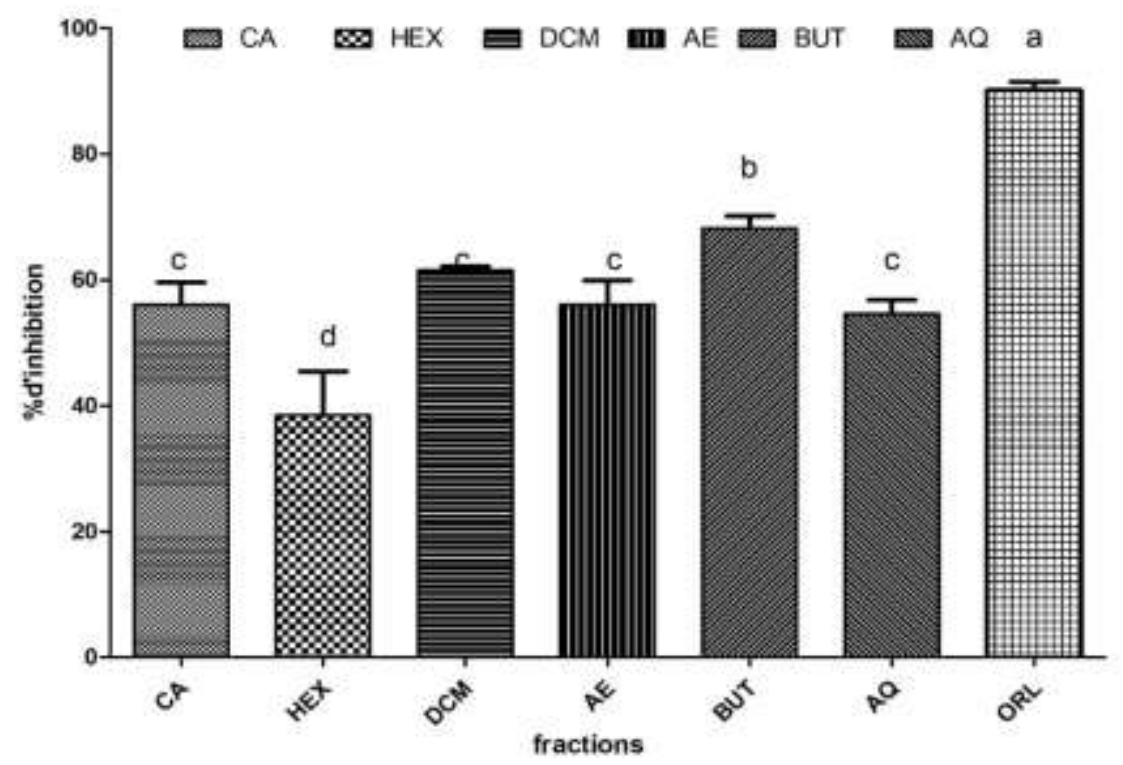

Fig-1: Pancreatic lipase inhibitory activity of the extracts

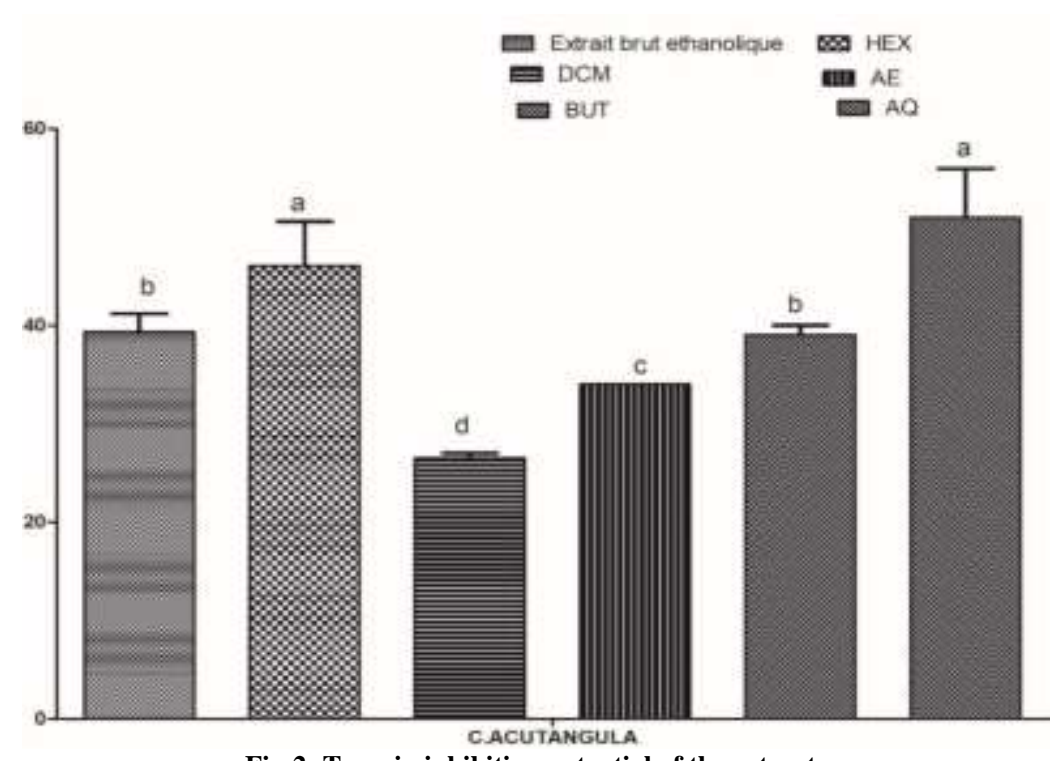

Fig-2: Trypsin inhibiting potential of the extracts

\section{Anorectic and slimming potential}

Figures 3 and 4 show the effect of the butanolic and ethyl acetate fractions on the weight and food taken of the treated animals. The ethyl acetate fraction gave the best activity on reducing body weight with $18.11 \%$ reduction to $50 \mathrm{mg} / \mathrm{kg}$ of body weight against control 1 (Standard diet) and control 2 (hyperlipid diet) which gave increases by weight of $16.61 \%$ and $34.83 \%$ respectively.
For the anorectic activity of the extracts, the ethyl acetate fraction showed the best activity with the lowest consumption of food at 50 and $75 \mathrm{mg} / \mathrm{kg}$.

The ethyl acetate fraction in general gave better activities compared to the butanolic fractions on the anorectic and slimming effect. The hyperlipid diet applied to animals has shown a potential to induce weight gain (obesity). 


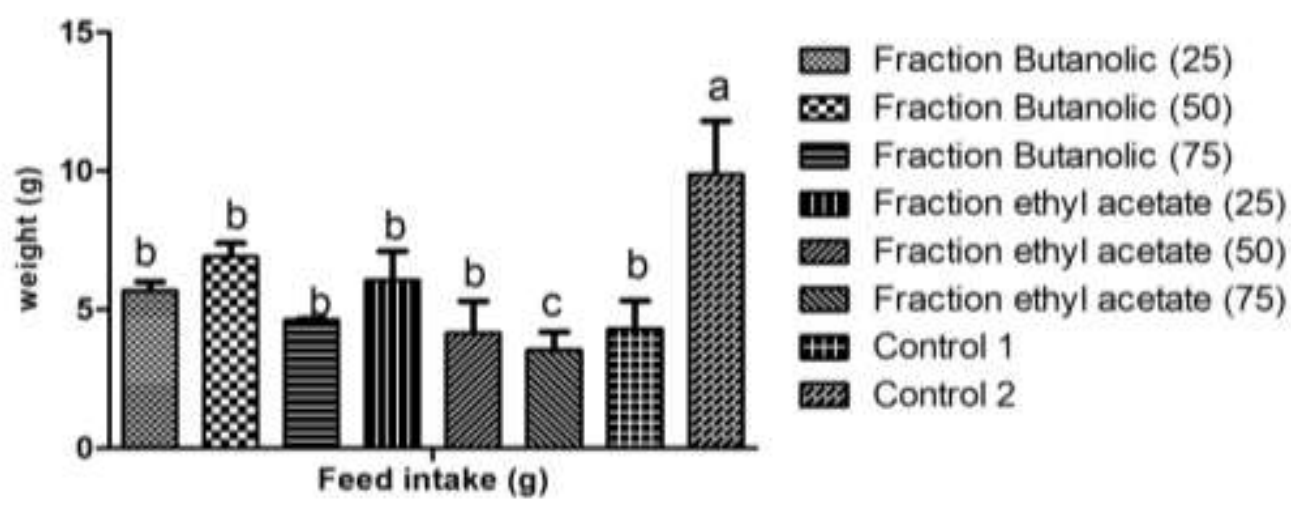

Fig-3: Anorectic effect of $C$. acutangula fractions
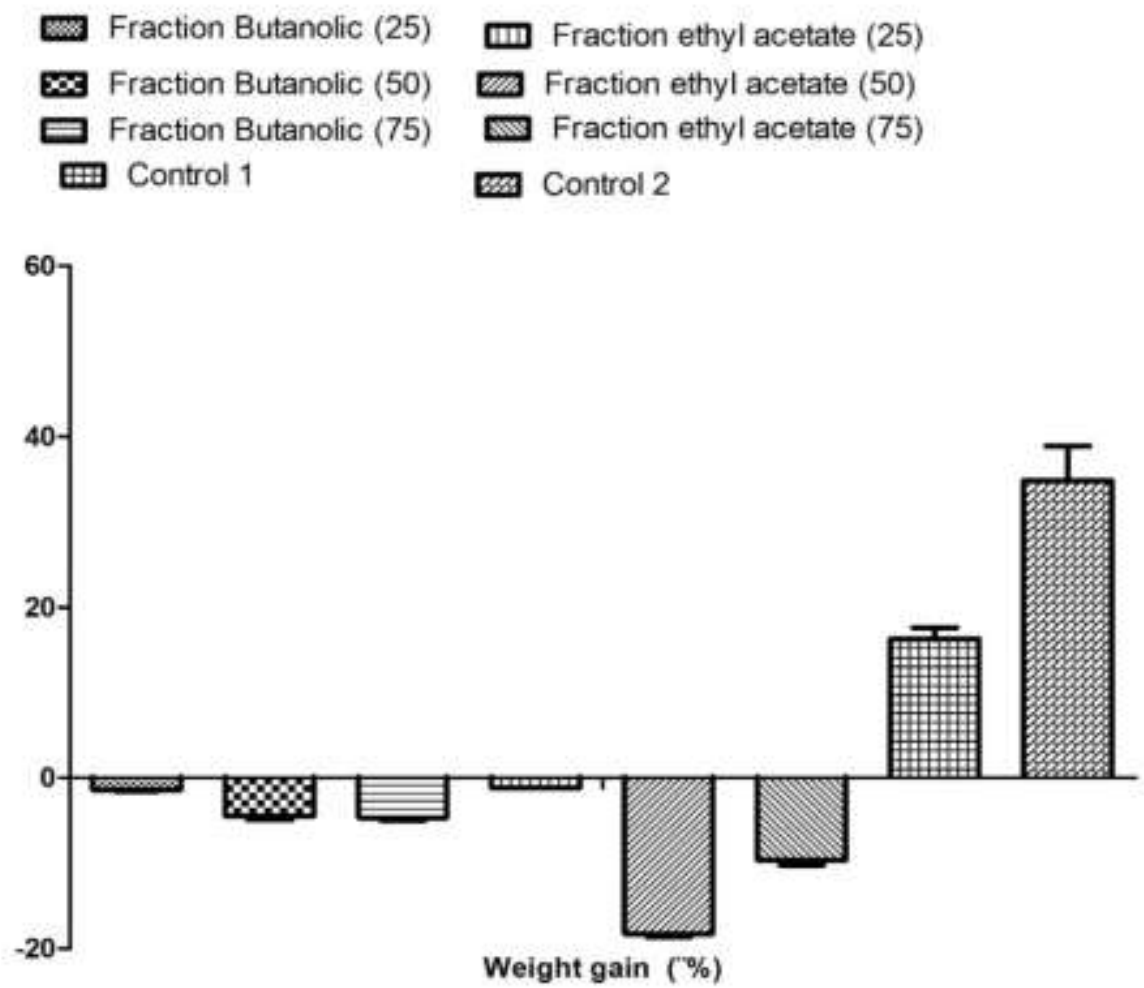

Fig-4: Effect of fractions on weight

\section{Effects of bioactive fractions on serum biochemical parameters}

In order to demonstrate the reducing activity of the extracts on serum lipid parameters in the obese, obesity was induced by a hyperlipid diet in animals and the latter are treated with the fractions of $C$. acutangula.

Fig-5 shows the effect of the fractions of the two plant extracts on the cholesterol, triglyceride, HDLc and LDLc serum levels of the treated animals. The butanolic and ethyl acetate fractions at different concentrations had no effect on serum cholesterol levels.

For the triglyceride level, the fractions reduced considerably this level in the treated animals. The ethyl acetate fraction at 25 and $75 \mathrm{mg} / \mathrm{kg}$ of body weight and the butanolic fraction at $50 \mathrm{mg} / \mathrm{kg}$ showed the best reductions in the rate of triglycerides with respectively $111.89 \pm 28.6 ; 108.35 \pm 10.5$ and $108.9 \pm 10.21 \mathrm{mg} / \mathrm{dl}$ against control 2 having received only the hyperlipid diet without treatment which gave a rate of $280 \pm 8.43$ $\mathrm{mg} / \mathrm{dl}$.

The hyperlipid diet led to a reduction in HDLc levels in animals that did not receive the plant extract. The butanolic and ethyl acetate fractions gave good activity on the HDLc level with a rate higher than that of control 2. The fractions thus presented a regulatory effect with respect to the HDLc level. The hyperlipid diet did not have a negative effect on the HDL level in the presence of the bioactive fractions.

All the fractions showed good activity on the LDLc level of the animals treated with a content lower than that of control 2 (animals fed on a hyperlipid diet) 
which gave the greatest content. The best activity was obtained with the butanolic fraction at $50 \mathrm{mg} / \mathrm{kg}$ of body weight.

Serum transaminase levels (ALAT, ASAT) have always been considered to be sensitive markers of liver damage. Table 1 shows the results of the effect of fractions on the level of ALAT and ASAT transaminases. The acetate ethyl fractions at $50 \mathrm{mg} / \mathrm{kg}$ and the butanolic fraction at 25 and $75 \mathrm{mg} / \mathrm{kg}$ showed the best activities on ASAT levels compared to control 2. All fractions except that of ethyl acetate at $25 \mathrm{mg} / \mathrm{kg}$ gave a good activity on the ALT level compared to control 2.

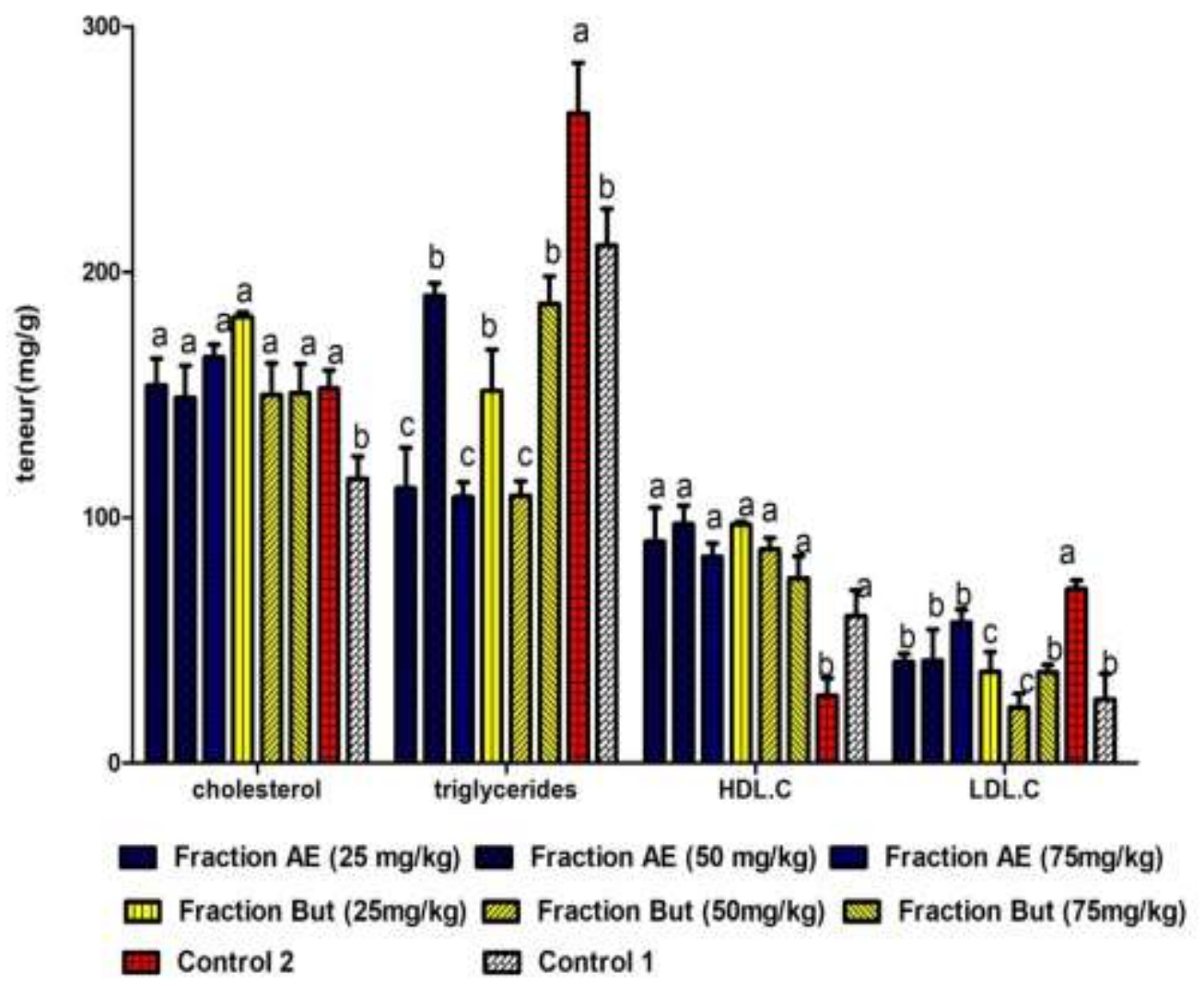

Fig-5: Effect of $C$. acutangula extract fractions on the serum lipid parameters of the treated animals

Table-1: Effect of fractions on hepatic parameters (ALAT, ASAT)

\begin{tabular}{|c|c|c|c|c|}
\hline Plant specie & Fractions & Dose (mg/kg) & ALAT (U/L) & ASAT (U/L) \\
\hline \multirow{6}{*}{ C. acutangula } & \multirow{3}{*}{ Fraction AE } & 25 & $47 \pm 9.89 a$ & $156 \pm 5.6 a$ \\
\hline & & 50 & $32.5 \pm 7.7 \mathrm{c}$ & $94.3 \pm 9.1 \mathrm{~d}$ \\
\hline & & 75 & $35 \pm 2.64 c$ & $119 \pm 12.7 b$ \\
\hline & \multirow{3}{*}{ Fraction But } & 25 & $35 \pm 4 c$ & $90.5 \pm 7.7 d$ \\
\hline & & 50 & $37.3 \pm 6.8 \mathrm{c}$ & $109.5 \pm 7.27 \mathrm{c}$ \\
\hline & & 75 & $35.5 \pm 6.3 c$ & $98.3 \pm 14.8 \mathrm{~d}$ \\
\hline \multirow[t]{2}{*}{ Control } & Control 1 & & $21 \pm 3 d$ & $110 \pm 7 c$ \\
\hline & Control 2 & & $43.5 \pm 4.9 b$ & $124.5 \pm 10.6 b$ \\
\hline
\end{tabular}

The potential of plant extracts fractions to reduce oxidative stress in the liver has been evaluated by their action on super oxide dismutase (SOD), catalase, malondialdehyde (MDA).

The extract fractions had no effect on the SOD rate (Figure 6), there is no statistical difference for this rate between the different groups.

Figure-7 shows us the effect of the fractions on the catalase level, the acetate ethyl fraction at $75 \mathrm{mg} /$ $\mathrm{kg}$ of body weight gave the best content compared to control 2 (Animals fed with a hyperlipid diet) which showed the lower grade.

The control 2 group on a hyperlipid diet showed an increase in MDA levels (Figure 8), however the extract fractions resulted in a reduction in this rate. The antioxidant effect of the fractions is characterized by a reduction in the level of MDA and an induction of the production of SOD and catalase. 


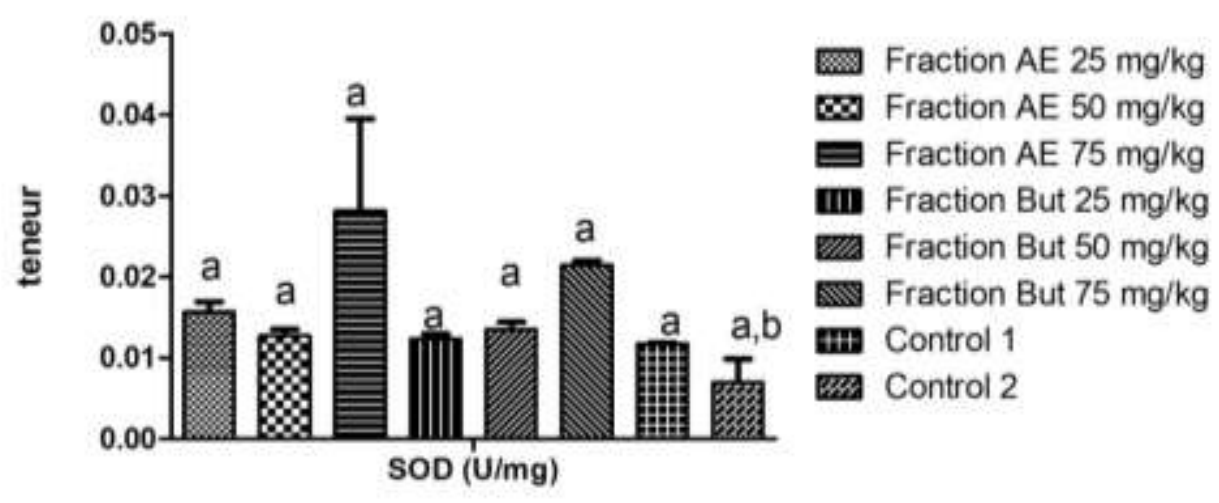

Fig-6: Activity of the extracts on super oxide dismutase
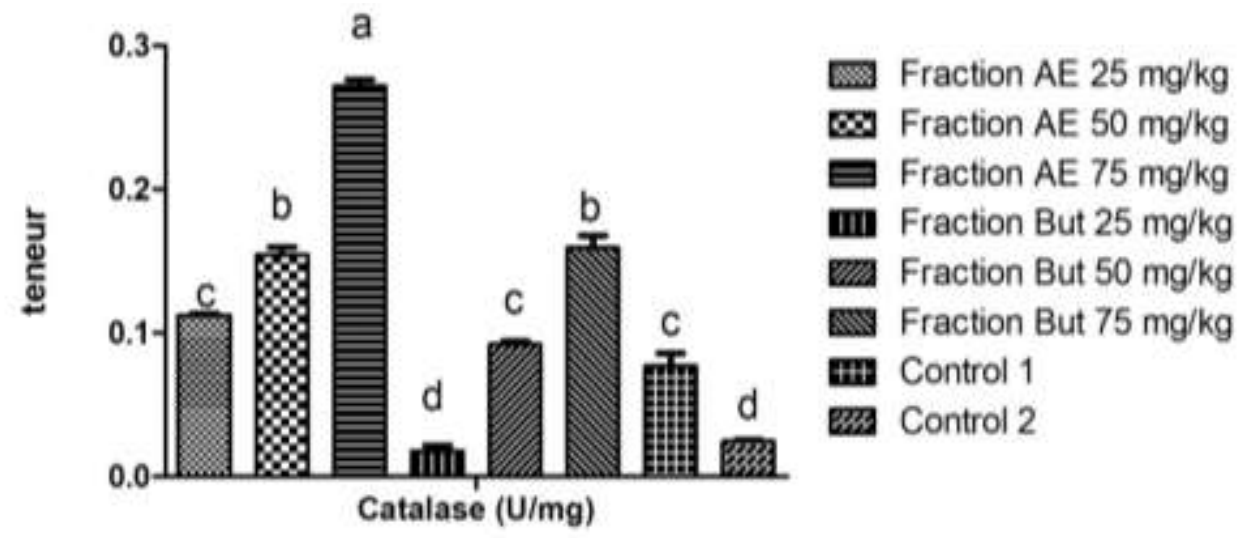

Fig-7: Effects of extracts on catalase activity
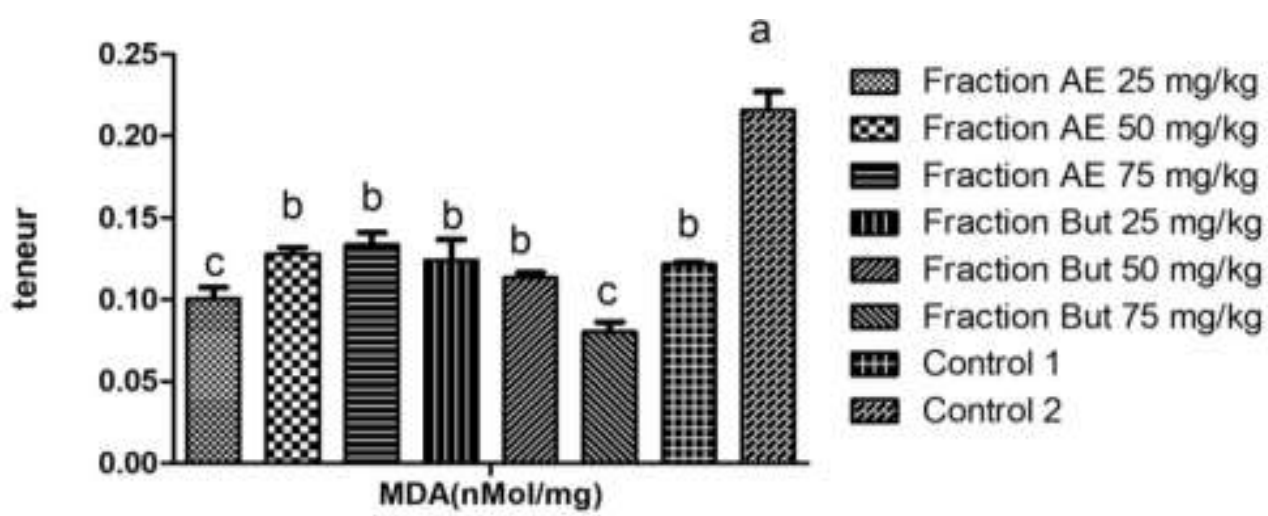

Fig-8: Activity of the extracts on the level of Malondialdehyde

\section{DISCUSSION}

The inhibition of digestion and absorption of nutrients is a promising alternative for the treatment of obesity. Pancreatic lipase is a enzyme key in the digestion of lipids for the absorption of triglycerides in the small intestine. This enzyme is responsible for the hydrolysis of 50 to $70 \%$ of dietary fats into fatty acids (FA) and monoglycerides [18]. Pancreatic lipase inhibition is an interesting targeted approach for the discovery of powerful anti-obesity agents for the treatment of obesity $[19,20]$.

The butanolic fraction of $C$. acutangula extract exhibited the best inhibitory activity of pancreatic lipase at $100 \mu \mathrm{g} / \mathrm{ml}$. The results corroborate with those of Young et al., in 2013 [21], who also found that a butanolic fraction of Polygonum cuspidatum are more active on pancreatic lipase. This fraction would therefore be rich in lipase inhibiting substances. A good number of natural antihyperlipidemic molecules have already been isolated from a few plants; there is the example of Epigallocatechin-3-gallate, kaempferol and quercetin which have shown an ability to inhibit pancreatic lipase [22]. The polyphenols in the pineapple extract have shown good inhibition of pancreatic lipase [23]. 
Trypsin is a proteolytic enzyme secreted by the pancreas in the form of an inactive precursor: trypsinogen. In the intestinal tract, trypsinogen is converted to trypsin by the action of enterokinase. Inhibitors of this enzyme work by reducing food intake and weight gain by increasing the level of neurohormone Cholecystokinin (CCK). CCK is an appetite suppressant hormone that sends signals of satiety to the brain. In the model animal, CCK induces a reduction in food consumption in the stomach and intestine, and in the central nervous system, leading to the development of "satiety behavior". CCK interacts with other hormones to control food intake and the satiety induced by this hormone is improved when combined with other anorectic signals [24].

Our fractions have shown good inhibition of trypsin and could therefore be used in the management of weight gain. Trypsin inhibitors are already used in the treatment of obesity [24]. A trypsin inhibitor isolated from peanuts caused a reduction in food intake, which resulted in a reduction in weight gain [25].

The butanolic and ethyl acetate fractions have given good results on digestive enzymes and have therefore been used for tests on the biochemical parameters of obesity in vivo.

The active fractions of the extracts showed a good reduction in body weight and food intake in the treated animals. The ethyl acetate fraction gave the best activity with a reduction in body weight to $18.11 \%$. The hyperlipid diet given to the animals caused a significant increase in weight in animals not treated with the extracts.

The activity of this fraction could be due to its richness in certain secondary metabolites such as flavonoids. Flavonoids are indeed endowed with antiobesity power. Certain flavonoids such as quercetin cause weight reduction by reducing lipid expression in fat cells [26]. The rutin found in oranges, watermelons also have anti-obesity activities [27]. This fraction which showed good inhibitory activity of pancreatic lipase could have reduced the weight gain of the animals treated by inhibiting this enzyme.

The high calorie diet for a weight price of animals caused a slight increase in transaminase ALAT and ASAT, Stranges S et al., 2004 [28] also found that the weight price caused an increase in liver enzymes which probably comes from following " fatty liver. The fractions by regulating the ALAT and ASAT levels could therefore participate in protecting the liver from steatosis in the event of obesity.

Obesity is most often accompanied by high triglyceride and LDLc levels followed by a reduction in HDLc as well as a reduction in the activity of antioxidant enzymes such as SOD, catalase [29].
Obesity, especially abdominal obesity, is associated with high levels of plasma triglycerides (TG) and low plasma levels of high density lipoproteins (HDL) and cholesterol [30].which are responsible for related pathologies [31].

This situation was observed in animals receiving only the hyperlipid diet during the experiment. The butanolic and ethyl acetate fractions all significantly reduced the serum triglyceride level of the treated animals compared to the hyperlipid control. The high LDLc levels accompanied by the reduction in HDLc levels are responsible for the cardiovascular disease observed in obese people [32]. The two fractions reduced the LDLc level in animal models and could therefore be used in the fight against obesity by reducing the cardiovascular diseases linked to it.

The hyperlipid diet caused low catalase content and high MDA production in animals. The activity of antioxidant enzymes is significantly low in case of obesity, this is involved in the development of health problems associated with weight gain. This pathology causes an increase in lipid peroxidation and a reduction in catalase, glutathione peroxidase and SOD [33]. The resulting oxidative stress plays an important role in the development and maintenance of obesityrelated comorbidity such as cardiovascular disease, insulin resistance [34].

The butanolic and ethyl acetate fractions exhibited good antioxidant activity by inhibiting the production of MDA (lipid peroxidation) and stimulating that of the production of catalase.

Lipid peroxidation is a very dangerous chain reaction for cells, indeed this phenomenon acts on cell membranes by altering their functionality (modification of their permeability, their fluidity, loss of activity of enzymes, receptors, etc.). Much other pathology is associated with lipid peroxidation. This is the case of neurodegenerative diseases (Alzheimer, Parkinson), diabetes, cancers, inflammatory diseases, aging [35].

Liu et al., 2014 [36] in their study using rats, found that quercetin increased the antioxidant enzymatic activity, such as that of glutathione peroxidase, glutathione reductase, superoxide dismutase (SOD) and catalase (CAT). Quercetin also prevents lipid peroxidation and thus helps to preserve the integrity of the membrane. The activity of the fractions on the catalase and the level of MDA could be explained by the presence of molecules such as flavonoids and triterpenes.

\section{CONCLUSION}

From this study we can retain that the fractions of $C$. acutangula showed a good inhibitory activity of the digestive enzymes such as pancreatic lipase and 
trypsin as well as a good potential of reduction of weight and food taken. The butanolic and ethyl acetate fractions significantly reduced the total triglyceride and serum LDLc levels and had antioxidant potential by reducing the level of MDA and stimulating the synthesis of antioxidant enzymes such as catalase and SOD. These two fractions would contain antiobesity molecules and could therefore be used in the implementation of a phytomedicine against this pathology.

\section{REFERENCES}

1. OMS. (2003). Obésité: Prévention et prise en charge de l'épidémie mondiale, Série de Rapports techniques; 894, 300.

2. Dennedy, M. C., \& Dunne, F. (2010). The maternal and fetal impacts of obesity and gestational diabetes on pregnancy outcome. Best Pract Res Clin Endocrinol Metab, 24: 573-589.

3. Mason, H. N., Crabtree, V., Caudill, P., \& Topp, R. (2008). Childhood obesity: a transtheoretical case management approach. J Pediatr Nurs, 23: 337-344.

4. Wright, S. M. and Aronne, L. J. (2012) Causes of obesity. Abdom Imaging 37: 730-732.

5. Kopelman, P. G. (2000). Obesity as a medical problem. Nature, 404: 635-643.

6. Claire, C., Ludivine, M., Alina, R., Charles, B., Marion, B., \& Sébastien, C. (2012). Traitement pharmacologique de l'obésité, Médecine. Clin Endocrinol Diabète, 61 :1-12.

7. Mahmoud, B., Zohreh E. K., Saki, E. F., Mahyar, J., \& Mahmoud, R. (2015). Obesity Phytotherapy: Review of Native Herbs Used in Traditional Medicine for Obesity. Journal of Evidence-Based Complementary \& Alternative Medicine, 1-7.

8. Tchamadeu, M. C., Dzeufiet, P. D. D., Nouga, C. C. K., Azebaze, A. G. B., Allard, J. P., Girolami, I. T., Kamtchouing, P., \& Dimo, T. (2010). Hypoglycaemic effects of Mammea africana (Guttiferae) in diabetic rats. Journal of Ethnopharmacology, 127:368-372.

9. Moro, C. O., \& Basile, G. (2000). Obesity and medicinal plants. Fitoterapia. 71(Suppl 1): S7382.

10. Van Heerden, F. R. (2008). Hoodia gordonii: A natural appetite suppressant. Journal of Ethnopharmacology, 119, 434-437.

11. Halaweish, F., Huntimer, E., \& Khalil, A. (2004). Polyoxy pregnane glycosides from Caralluma retrospiciens. Phytochem Anal. 15:189-194.

12. Changhyun, R., \& Uhee J., (2012). Screening of crude plant extracts with antiobesity activity. International Journal of Molecular Sciences, 13:1710-1719.

13. Arefrad, M., Jelodar, N. B., Nematzadeh, G., \& Kazemitaba, S. (2013). Influence of Genotype Variation on Trypsin and Chymotrypsin Inhibitors levels of Seed Storage Proteins composition in Soybean [Glycine max (L.) Merrill]. International
Journal of Agronomy and Plant Production, 4(12):2877-2884.

14. Mei-Yin, C., Yu-Hua, K., Jin-Ming, C., Chih-Min, Y., \& Chao-Hsiang, C. (2016). Effects of herbal mixture extracts on obesity in rats fed a high-fat diet. Journal of Food and Drug Analysis, 24(3):594-601.

15. Misra, H. P., \& Fridovich, I. (1972). The role of superoxide anion in the autoxidation of epinephrine and a simple assay for superoxide dismutase. Journal of Biological chemistry, 247(10), 3170-3175.

16. Beers, F., \& Sizer, J. R. (1951). Cambridge, a spectrophotometric method for measuring the breakdown of hydrogen peroxide by catalase. $J$ Biol. Chem, 195:133-140.

17. Ohkawa, H., Ohishi, N. and Yagi, K. (1979). Assay for lipid peroxidation in animal tissues by thiobarbituric acid reaction. Ann Biochem, 95, 351-358.

18. Gyo-Nam, K., Mi-Rae, S., SungHo, S., Reum, A. L., Joo, Y. L., Bu-Il, S., Min, Y. K., Tae, H. K., Jeong, S. N., Man, H. R., \& Seong-Soo, R. (2016). Study of Antiobesity Effect through Inhibition of Pancreatic Lipase Activity of Diospyros kaki Fruit and Citrus unshiu Peel. BioMed Research International, 7.

19. Thomson, A. B., de Pover, A., Keelan, M., Jarocka-Cyrta, E., \& Clandinin, M. T. (1997). Inhibition of lipid absorption as an approach to the treatment of obesity. Meth Enzymol. 286:3-41.

20. Tsujita, T., Ninomiya, H., \& Okuda, H. (1989). pNitrophenyl butyrate hydrolyzing activity of hormone-sensitive lipase from bovine adipose tissue. J Lipid Res, 30, 997-1004.

21. Young, S. K., Yun, M., Joo, H. K., \& Jin, S. K., (2013). Polygonum cuspidatum inhibits pancreatic lipase activity and adipogenesis via attenuation of lipid accumulation. BMC Complementary and Alternative Medicine, 13(282):1-10.

22. Sergent, T., Vanderstraeten, J., Winand, J., Beguin, P., \& Schneider, Y. (2012). Phenolic compounds and plant extracts as potential natural anti-obesity substances. Food Chemistry, 135:6873.

23. Bouayed, J., Hoffmann, L., \& Bohn, T. (2011). Total phenolics, flavonoids, anthocyanins and antioxidant activity following simulated gastrointestinal digestion and dialysis of apple varieties: Bioaccessibility and potential uptake. Food Chem. 128, 14-21.

24. Lima, V. C. O. D., Piuvezam, G., Maciel, B. L. L. and Morais, A. H. D. A. (2019). Trypsin inhibitors: promising candidate satietogenic proteins as complementary treatment for obesity and metabolic disorders? Journal of enzyme inhibition and medicinal chemistry, 34 (1):405419.

25. Serquiz, A. C., Machado, R. J. A., Serquiz, R. P., Lima, V. C. O., de Carvalho, D. M. C., Carneiro, 
M. A. A., Maciel, B. L. L., Uchôa, A. F., Santos, E. A., Ana, H. A., \& Morais, A. H. A. (2016). Supplementation with a new trypsin inhibitor from peanut is associated with reduced fasting glucose, weight control, and increased plasma CCK secretion in an animal model. Journal of Enzyme Inhibition and Medicinal Chemistry, 31(6): 12611269.

26. Yang, J. Y., Della-Fera, M. A., Rayalam, S., Ambati, S., Hartzell, D. L., Park, H. J., \& Baile, C. A. (2008). Enhanced inhibition of adipogenesis and induction of apoptosis in 3t3-11 adipocytes with combinations of resveratrol and quercetin. Life Sci, 82:1032-1039.

27. Kreft, S., Knapp, M., \& Kreft, I. (1999). Extraction of rutin from buckwheat (fagopyrum esculentum moench) seeds and determination by capillary electrophoresis. J Agric Food Chem, 47:4649-465.

28. Stranges, S., Dorn, J. M., Muti, P., Freudenheim, J. L., Farinaro, E., \& Russell, M. (2004). Body fat distribution, relative weight and liver enzymes levels: A population based study. Hepatology, 39(3):754-763.

29. Alba, F., Eduardo, M., Mirandeli, B., Jaime, E., Ángel, M., Cesar, E., Durante, M., Graciela, S., Carmen, V., \& José, A. M., (2011). Inflammation, Oxidative Stress, and Obesity. Int J Mol Sci, 12, 3117-3132.

30. Després, J. P., Moorjani, S., Tremblay, A., Ferland, M., Lupien, P. J., Nadeau, A., \& Bouchard, C. (1989). Relation of High Plasma Triglyceride Levels Associated With Obesity and
Regional Adipose Tissue Distribution to Plasma Lipoprotein-Lipid Composition in Premenopausal Women. Clin Invest Med, 12(6):374-80.

31. Boudewijn, K., Willem, J., Elte, F., \& Cabezas, M. C. (2013). Dyslipidemia in Obesity: Mechanisms and Potential Targets. Nutrients, 5(4):1218-1240.

32. Codoner-Franch, P., Murria-Estal, R., TortajadaGirbés, M., del CastilloVillaescusa, C., VallsBellés, V., \& Alonso-Iglesias, E. (2010). New factors of cardiometabolic risk in severely obese children: influence of pubertal status. Nutr Hosp. 25: 845-851.

33. Noeman, S. A., Hamooda, H. E., \& Baalash, A. A. (2011). Biochemical Study of Oxidative Stress Markers in the Liver, Kidney and Heart of High Fat Diet Induced Obesity in Rats. Diabetology \& Metabolic Syndrome, 3(17):1-8.

34. Marcela, A. S., Tarraf, H. S., Nicoletti, C. F., Percário, S., Oliveira, B. A. P., Oliveira, C. C., Gregório, M. L., Pinhanelli, V. C., \& Dorotéia, R. S. (2018). Oxidative Stress and Biochemical Parameters in Childhood Obesity. Austin J Nutri Food Sci. 6(1), 1-5.

35. Cillard, J., \& Cillard, P. (2006). Mécanismes de la peroxydation lipidique et des anti-oxydations. OCL Oleagineux- Corps gras. Lipides, 13(1):2430

36. Liu, H., Guo, X., Chu, Y., \& Lu, S. (2014). Heart protective effects and mechanism of quercetin preconditioning on anti-myocardial ischemia reperfusion (IR) injuries in rats. Gene, 545(1):14955. 